\title{
Control of the illegal use of clenbuterol in bovine production
}

\author{
Assunção Cristino ${ }^{a}$, Fernando Ramos ${ }^{b}$, , Maria Irene Noronha da Silveira ${ }^{b}$ \\ a INFARMED-DOCQ (Farmacotecnia e Biofarmácia), Parque de Saúde de Lisboa, Avenida do Brasil 53, 1749-004 Lisbon, Portugal \\ ${ }^{\mathrm{b}}$ Laboratório de Bromatologia, Hidrologia e Nutrição, Faculdade de Farmácia, Universidade de Coimbra, R. Norte, 3000-295 Coimbra, \\ Portugal
}

Received 3 November 2002; received in revised form 28 January 2003; accepted 28 January 2003

\begin{abstract}
This study is based on a plan of collecting different matrices (hair, eye, muscle, liver and kidney) in order to define a strategy for the control of the illegal use of clenbuterol in bovine production. Of all matrices utilised, hair is recommended for the analytical control of clenbuterol in living animals, due to its being permanently available and easy to collect. The eye, or rather the retina, is the matrix which gives the most trustworthy result, after the animal slaughter, and the one that best helps in the determination of the illegal use of clenbuterol in a perspective of gradual food safety improvement.
\end{abstract}

(C) 2003 Elsevier Science B.V. All rights reserved.

Keywords: Clenbuterol; Bovine; Control; Hair; Retina; Gas chromatography-mass spectrometry

\section{Introduction}

The number of medicines used to promote animal growth has been increasing exponentially, mainly due to the modern practices of intensive animal husbandry.

Although clenbuterol (4-amino-3,5-dichloro- $\alpha$ [(tert-butylamino)methyl]benzyl alcohol hydrochloride) is authorised in the veterinarian therapeutics of bovines, equines and pet animals as a bronchodilatant or as a tocolitic agent in cows [1]; it has also been illegally used [2,3] to promote

\footnotetext{
* Corresponding author. Tel.: +351-239-859994; fax: +351239-827126.

E-mail address: fjramos@ci.uc.pt (F. Ramos).
}

animal growth, causing a considerable increase in muscular mass and, at the same time, a decrease in fat accumulation [4,5]. However, in some cases, the presence of non-negligible amounts of drug residues in meat is a real public health problem and various food poisoning situations have been described as being due to clenbuterol residues in liver and meat [6-13].

In order to define a strategy for the control of the illegal use of clenbuterol in bovine production, a plan of collecting different matrices (hair, eye, muscle, liver and kidney) was performed. Thus, the purpose of this study was to define a possible ideal moment of analysis for each one of the utilised matrices, which must be applied to meet the current quality standards of food safety. 


\section{Experimental}

\subsection{Reagents and materials}

Standards of clenbuterol and hexadeutered clenbuterol (d6) were supplied by Interchim (Montluçon, France) and by RIVM (Bilthoven, the Netherlands), respectively. Derivatiser reagent was prepared by mixing the three reagents, $N$ methyl- $N$-trimethylsilyl-trifluoracetamide

(MSTA; Macherey-Nagel, Düren, Germany), ditioeritritol (DTE; Merck, Lisbon, Portugal) and trimethyliodosilane (TMIS; Sigma, Madrid, Spain) in the proportion $5 \mathrm{ml}: 20 \mathrm{mg}: 20 \mu \mathrm{l}$ (MSTA:DTE:TMIS). Purified water was obtained with a Milli-Q Plus system by Millipore (Bedford, MA, USA) and all other reagents utilised were from Merck.

Homogenisation and clenbuterol residue extraction from liver, kidney and muscle samples were performed with a Stomacher ${ }^{\circledR}$ (IUL Instruments, Anatrom, Oporto, Portugal) and with an ultrasonic probe (Vibra Cell CV17, Sonics \& Materials, Danbury, CT). Extract purification was undertaken by solid-phase extraction (SPE) on a vacuum manifold system with Chromabond $\mathrm{C}_{18}$ and mixed-phase $\left(\mathrm{C}_{8}+\mathrm{SCX}\right) 500 \mathrm{mg}$ columns, respectively, from Macherey-Nagel and from Worldwide Monitoring, USA, supplied by Reagente 5 (Oporto, Portugal). Centrifugation was done with a minimal $3000 \times g$ force (Selecta Meditronic, Barcelona, Spain), and the $\mathrm{pH}$ evaluations were done with a WPA CD7400 potentiometer (Cambridge, UK). Material for derivatisation and automatic injection used for chromatography was supplied by Chromacol (Dias de Sousa, Lisbon, Portugal).

Clenbuterol determination was achieved by gas chromatography-mass spectrometry (GC-MS) with Hewlett-Packard (HP) equipment (Soquímica, Lisbon, Portugal), comprising an HP5890 Series II gas-liquid chromatograph, an HP6890 automatic injector, an HP5972 MSD detector, an HP Vectra VL2 4/50 computer, an HP DeskJet 520 printer, and an HP-5MS column with a length of $30 \mathrm{~m}, 0.25 \mathrm{~mm}$ of internal diameter and $0.25 \mu \mathrm{m}$ of film thickness. The gases utilised, nitrogen N45 and helium N55, were supplied by Sogafer (Coimbra, Portugal).

\subsection{Samples}

Samples were collected in two slaughterhouses of Leiria district (Portugal) from 13 calves, younger than 12 months old, with various hair colours. All these animals were suspected of having been fattened through the use of clenbuterol. The amounts of hair $( \pm 15 \mathrm{~g})$, eye (2), muscle $( \pm 50 \mathrm{~g})$, liver $( \pm 50 \mathrm{~g})$ and kidney (1) collected from each animal were transported, on the sampling day, in a refrigerated box $\left(4 \pm 2{ }^{\circ} \mathrm{C}\right)$ to the laboratory, where they were kept in a deep freezer $\left(-20 \pm 2{ }^{\circ} \mathrm{C}\right)$ until the beginning of the analysis.

\subsection{Sample preparation}

\subsubsection{Hair}

Common scissors were used to cut hair samples from each slaughtered animal. Hair was washed with a solution of Tween 80 at 5\% in water. The sample was then rinsed in purified water as often as necessary until the washing water was clear. Hair sample was dried in an oven at $40^{\circ} \mathrm{C}$, and subsequently cut into small pieces of $1-2 \mathrm{~mm}$. An amount of $1.0 \pm 0.1 \mathrm{~g}$ was placed in a centrifuge tube to which $3 \mathrm{ml}$ of $\mathrm{NaOH} 2 \mathrm{M}$ and $100 \mu \mathrm{l}$ of internal standard, hexadeutered clenbuterol in a methanolic solution of $1 \mu \mathrm{g} / \mathrm{ml}$, were added. Following homogenisation, the sample was digested at $80 \pm 5{ }^{\circ} \mathrm{C}$ for $1 \mathrm{~h}$, with agitation every 15 min $[14,15]$. After cooling to room temperature, the $\mathrm{pH}$ of the digest was set to values of $6.0 \pm 0.5$ with $2 \mathrm{M} \mathrm{HCl}$. A centrifugal step was performed for $5 \mathrm{~min}$ and the supernatant was filtered. The sediment was resuspended with $5 \mathrm{ml}$ of phosphate buffer ( $\mathrm{pH} \quad 6.0 \pm 0.1 ; 0.1 \mathrm{M}$ ) and was again centrifuged for $5 \mathrm{~min}$. The second supernatant was also filtered and mixed with the previous one.

\subsubsection{Liver, muscle and kidney}

An aliquot of $10 \pm 0.1 \mathrm{~g}$ of liver, muscle or kidney, previously homogenised in a meat grinder, was subjected to a Stomacher ${ }^{\circledR}$ extraction with acetate buffer ( $\mathrm{pH} 5.9 \pm 0.1 ; 0.2 \mathrm{M})$ and subsequently submitted to ultrasonification with a 
probe. An $100 \mu$ of internal standard solution was then added and the sample was set to $\mathrm{pH} 1.0 \pm 0.3$ with concentrated perchloric acid and centrifuged. Supernatant was removed and the $\mathrm{pH}$ was again adjusted to $9.5 \pm 0.3$ with ammonia at $32 \%$. Alkalised solution was saturated with sodium chloride and submitted to a liquid-liquid extraction through a mixture of isopropanol:ethyl acetate $(40: 60, \mathrm{v} / \mathrm{v})$. Organic phase was recovered and the extraction was repeated under the abovementioned conditions. The two portions of the organic phase were joined together before being evaporated almost until dry in a rotavapor [1618]. The residue was recovered with $10 \mathrm{ml}$ of phosphate buffer.

\subsubsection{Eye}

Collection of bovine eyes was made with disposable surgical gloves and scalpels. The whole eyeball and part of the optical nerve were removed. Retina separation from the remaining components of the eye was made from the whole, semi-frozen eye, which was cut in half. Crystalline, and vitreous and aqueous humours were eliminated. Retina of both halves was separated from the other eye components, cut and weighed. Retina was cut into small fragments and placed in a centrifuge tube, where $10 \mathrm{ml}$ of acetate buffer $(\mathrm{pH}$ $5.9 \pm 0.1 ; 0.2 \mathrm{M}$ ) and $100 \mu \mathrm{l}$ of internal standard were added. After vortex homogenisation for 1 min, the sample was placed in an ultrasound bath for $10 \mathrm{~min}$, following by centrifugation. Supernatant was filtered, and $\mathrm{NaOH} 2 \mathrm{M}$ was added until a final $\mathrm{pH}$ of $9.5 \pm 0.5$ was attained [19]. After this step, disposable material and eyeball rests, retina included, were properly stored and incinerated according to the Portuguese BSE program eradication.

\subsection{Solid-phase extraction}

Extracts of hair, liver, muscle and kidney samples were purified by SPE with mixed-phase columns. Sorbent was activated with methanol, water and phosphate buffer, following which the respective extract was passed through the column. Washing step was done with acetic acid and methanol, and the sorbent was dried, after each washing solvent, through centrifugation. Elution of the analyte was done with ethyl acetate:ammonia $32 \%[20,21]$.

Retina extracts were submitted to SPE with $\mathrm{C}_{18}$ columns. Sorbent activation was done with methanol and water, after which the sample extract was passed through. Columns were washed with water and the excess solvent was eliminated by centrifugation. Clenbuterol was eluted with methanol [21].

\subsection{Derivatisation}

Eluates were evaporated to dryness under a nitrogen stream at $45^{\circ} \mathrm{C}$. The residue was dissolved in methanol and transferred to a derivatisation vial. Methanol was also evaporated to dryness under the conditions mentioned above for the eluates, and the resulting dry residue was redissolved with $50 \mu \mathrm{l}$ of derivatisation reagent. After vial encapsulation, derivatisation was undertaken for $20 \mathrm{~min}$ at $60{ }^{\circ} \mathrm{C}$ [12].

\subsection{Chromatography}

An aliquot of $2 \mu \mathrm{l}$ was injected into the GC-MS system in splitless mode, $1 \mathrm{~min}$, using helium as carrier gas. Injector and detector temperatures were 260 and $280{ }^{\circ} \mathrm{C}$, respectively, and determination was done in the electron impact mode with selective ion monitoring: $\mathrm{m} / \mathrm{z} 86$ and 92, respectively, for clenbuterol and hexadeutered clenbuterol, and $\mathrm{m} / \mathrm{z}$ 300, 335 and 337 for both. The results were obtained through the ratio between the ion peak areas: $\mathrm{m} / \mathrm{z} 86$ for clenbuterol and $\mathrm{m} / \mathrm{z} 92$ for hexadeutered clenbuterol, internal standard [12].

\section{Results and discussion}

Figs. 1 and 2 show, respectively, chromatograms of hair and retina samples from the animal identified as No. 6. Table 1 shows the obtained results. It will be noted that no clenbuterol was detected, in any of the matrices analysed, in 8 of the 13 animals.

According to the present results, it is evident that hair and retina are the most important matrices in order to determine the highest clenbu- 


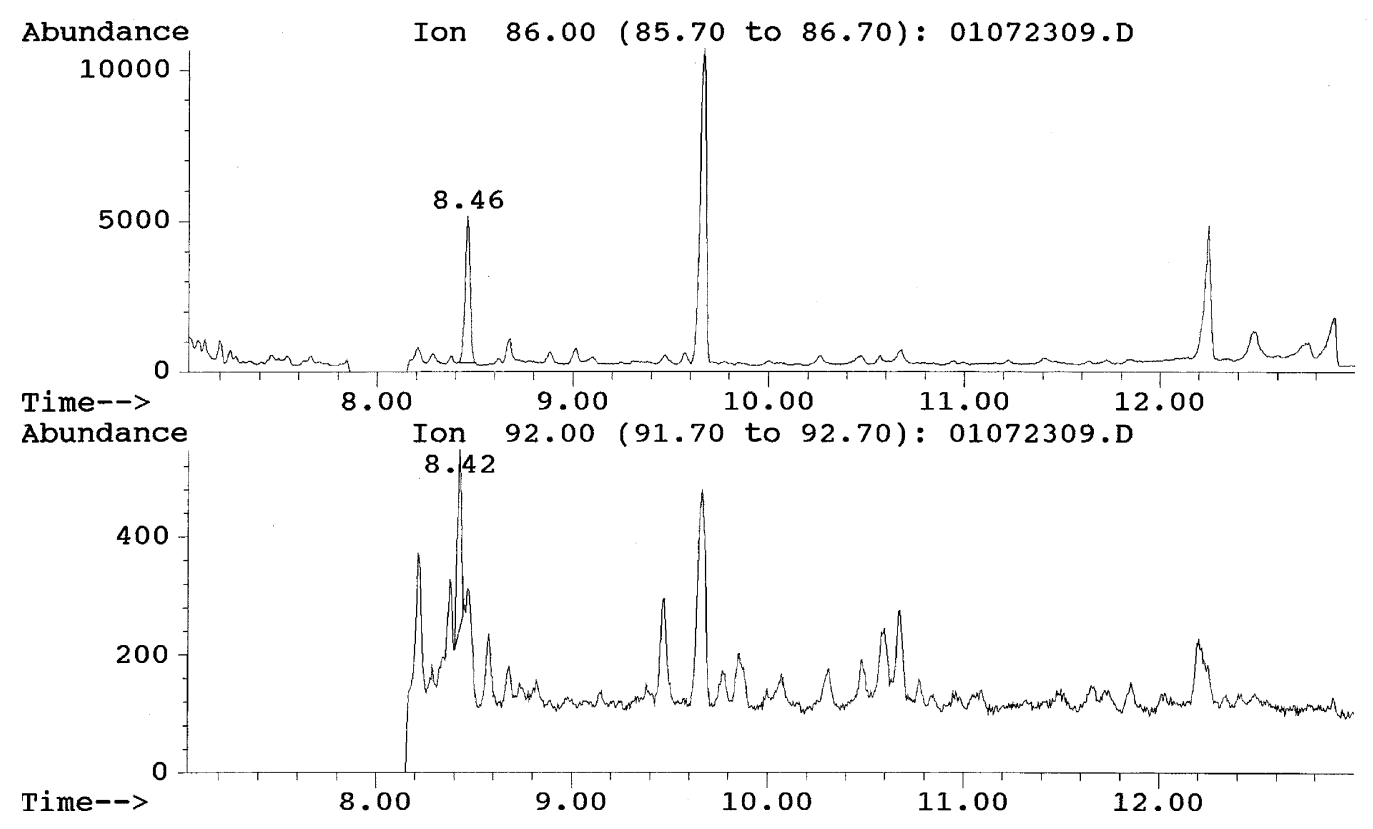

Fig. 1. Chromatogram of a hair sample with clenbuterol.

terol concentrations. This could be explained because the pharmacokinetics of clenbuterol in retina and hair, on one side, and in liver, kidney and muscle, on the other, were different: liver, kidney and muscle are very well irrigated blood tissues in opposition to hair and eye. So, clenbuterol accumulates in these later tissues, particularly, if they are pigmented [22,23].

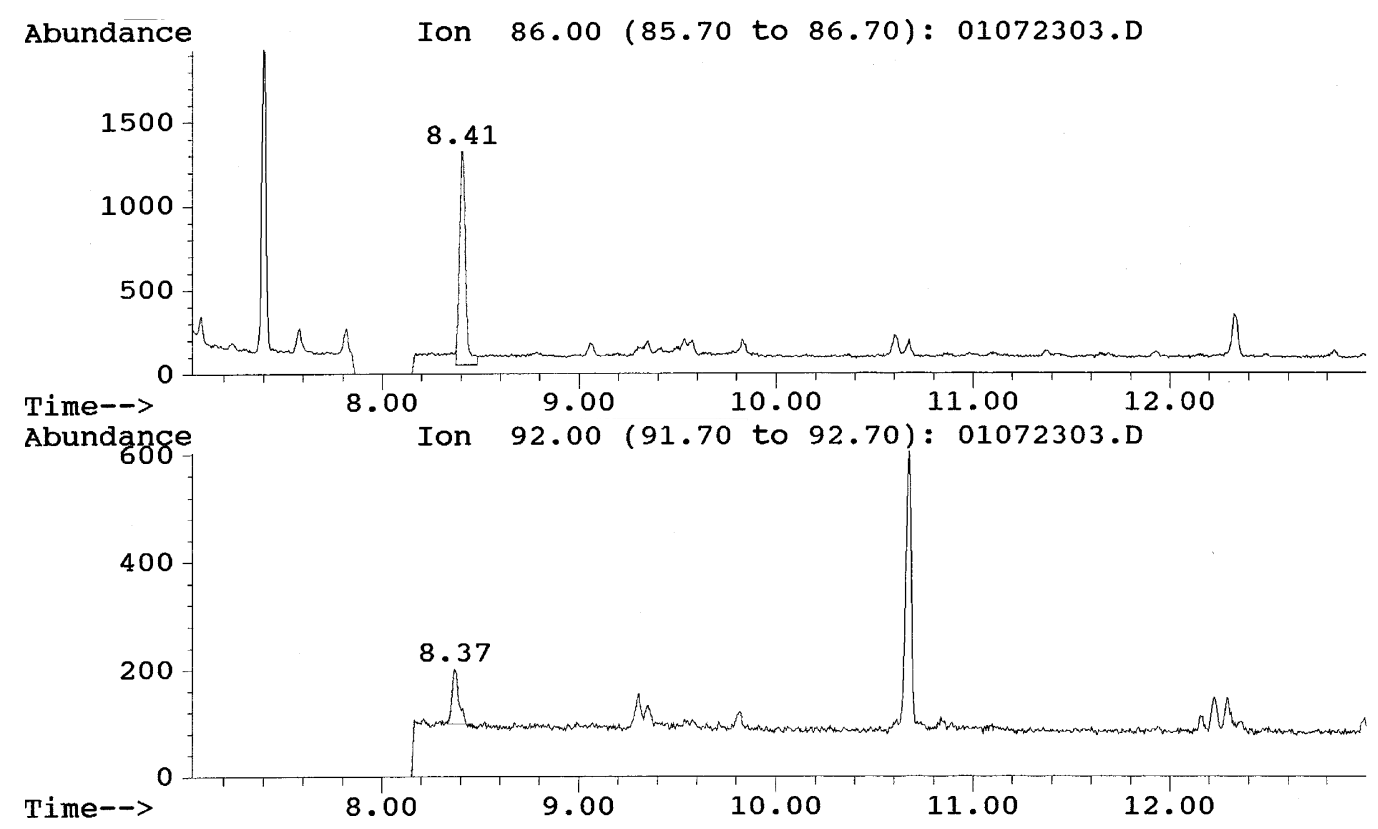

Fig. 2. Chromatogram of a retina sample with clenbuterol. 
Table 1

Clenbuterol concentrations in the different matrices (ng/g)

\begin{tabular}{|c|c|c|c|c|c|c|}
\hline Animal & Hair & Retina & Liver & Muscle & Kidney & Hair colour \\
\hline 1 & 1655.5 & 397.8 & 32.0 & 3.2 & 2.7 & Black \\
\hline 2 & 8.6 & ND & ND & ND & ND & Black \\
\hline 3 & ND & ND & ND & ND & ND & Black \\
\hline 4 & ND & ND & ND & ND & ND & Black \\
\hline 5 & ND & ND & ND & ND & ND & Black \\
\hline 6 & 123.9 & 37.3 & 4.1 & 1.6 & 1.5 & Brown \\
\hline 7 & ND & ND & ND & ND & ND & Brown \\
\hline 8 & ND & ND & ND & ND & ND & Brown \\
\hline 9 & ND & ND & ND & ND & ND & Brown \\
\hline 10 & 20.2 & 8.9 & 0.9 & ND & ND & Blond \\
\hline 11 & ND & ND & ND & ND & ND & Blond \\
\hline 12 & ND & 15.0 & 2.2 & ND & ND & White \\
\hline 13 & ND & ND & ND & ND & ND & White \\
\hline
\end{tabular}

ND - not detected.

Hair, in fact, is considered as the best matrix to determine the presence of clenbuterol in living bovines [15,24-28]. The possibility of an easy, simple and fast sample collection, with no added danger for the operator, as is the case with blood or urine collections, is an advantage which cannot be disregarded. However, as can be proved by analysing the results, the hair colour has a major importance in clenbuterol accumulation [29], particularly when comparing the rates found in hair and retina samples of the same animal. The relation between clenbuterol concentrations found in hair and retina (hair/retina) can vary between a minimum of zero, with no perceivable relation, in the case of a white-haired bovine, and a maximum of about 4/1, in the case of black-haired bovines, in-between values of $3 / 1$ being found in brownhaired animals, or $2 / 1$ when the bovine hair is blonde.

If the relation of clenbuterol concentrations noted between hair and retina depends on the colour of the animal's hair, the relation between the concentrations found in the retina and liver appears to remain relatively constant, at an approximate value between 6.8 and 12.4 (average $=9.56 \pm 2.31, n=4$ ).

Clenbuterol concentration in muscle and kidney, where it was possible to determine its presence, enable that these matrices present the lowest concentrations found with nearly identical values, even slightly lower for kidney samples.

Thus, it can be concluded that hair was the best matrix for clenbuterol control in living bovines, except when its colour is white, which can be corroborated through the results obtained with animal No. 12.

Liver, the alimentary matrix where clenbuterol remains in greater amounts and for a longer period, has been responsible for the highest number of intoxications attributed to the referred substance [8-12]. Consequently, its analysis is compulsory whenever there are suspicions of clenbuterol intoxication.

Eye, or rather retina, is the matrix which gives the most trustworthy result; having no immediate alimentary or commercial value, its analysis can be recommended for all bovines suspected of illegal fattening. The speed and simplicity of the analysis, particularly when compared with the other matrices under discussion, is an advantage which cannot be disregarded, even though there is inconvenience in providing a very small amount of sample for analysis - an average of $1.5-2.5 \mathrm{~g}$ for both eyes together. On the other hand, considering that the accumulation of clenbuterol in the retina happens in greater amounts than in any edible matrix and that the contents in the liver may be deducted from the value determined in the retina, it is clear that this matrix must be advised 
as a compulsory reference matrix for any analyses scheduled for immediately after the slaughter.

\section{Acknowledgements}

The authors are grateful to the Portuguese Foundation for Science and Technology (CEFFCT) for supporting this study. The authors are also grateful to the Portuguese Inspection for Economical Activities (IGAE) for sampling facilities.

\section{References}

[1] M.S. Lopes, Promoarte, Lda., Lisbon, 2000, pp. 221-222.

[2] Decreto-Lei No. 148/99, Diário da Republica, I série-A 103 (99-05-04), pp. 2354-2370.

[3] Directive No. 96/22/CE of 29 April 1996, Off. J. Eur. Community L125 (1996) 3-9.

[4] J.P. Hanrahan, Beta-agonists and their effects on animal growth and carcass quality, Elsevier, London, 1987.

[5] F. Ramos, M.I.N. da Silveira, Rev. Port. Ciênc. Vet. 97 (2002) 51-62.

[6] G. Brambilla, T. Cenci, F. Franconi, R. Galarini, A. Macri, F. Rondoni, M. Strozzi, A. Loizzo, Toxicol. Lett. 114 (2000) 47-53.

[7] G. Brambilla, A. Loizzo, L. Fontana, M. Strozzi, A. Guarino, V. Soprano, J. Am. Med. Assoc. 278 (1997) 635.

[8] J.B. Garay, J.F.H. Jiménez, M.L. Jiménez, M.V. Sebastián, J.P. Matesanz, P.M. Moreno, J.R. Galiana, Rev. Clin. Esp. 197 (1997) 92-95.

[9] J.F. Martínez-Navarro, Lancet 336 (1990) 1311.

[10] C. Pulce, D. Lamaison, G. Keck, C. Bostvironnois, J. Nicolas, M. Mora, A. Colmant, Bull. Epidemiol. Hebd. 5 (1991) 17-18.

[11] F. Ramos, P. Carrola, A.I. Silva, J.M. Silva, J.J. Moura, M.I.N. da Silveira, in: R. Cabral (Ed.), Food SafetyProceedings Book, Porto, 2000, pp. 201-204.
[12] F. Ramos, A. Cristino, P. Carrola, T. Eloy, J.M. Silva, M.C. Castilho, M.I.N. da Silveira, Anal. Chim. Acta, in press.

[13] V. Sporano, L. Grasso, M. Esposito, G. Oliviero, Vet. Hum. Toxicol. 40 (1998) 141-143.

[14] C.A. Fente, B.I. Vázquez, C. Franco, A. Cepeda, P.G. Gigosos, J. Chromatogr. B 726 (1999) 133-139.

[15] F. Ramos, P. González, A. Oliveira, A. Almeida, C. Fente, C. Franco, A. Cepeda, M.I.N. da Silveira, J. Liq. Chromatogr. Rel. Technol. 24 (2001) 251-263.

[16] S. Collins, M. O'keeffe, M. Smyth, Analyst 119 (1994) 2671-2674.

[17] M.-P. Montrade, B. le Bizec, F. Monteau, F. André, Food Addit. Contam. 12 (1995) 625-636.

[18] F. Ramos, M.C. Castilho, M.I.N. da Silveira, Rev. Port. Farm. 1 (2000) 117-123.

[19] P.G. Gigosos, T.F. Fernandez, O.C. Mariz, C.A.F. Sampayo, C.F. Abuin, A.C. Saez, J. Chromatogr. B 677 (1996) 167-171.

[20] M.-P. Montrade, B. le Bizec, F. Monteau, B. Siliart, F. André, Anal. Chim. Acta 275 (1993) 253-268.

[21] F. Ramos, M.C. Bañobre, M.C. Castilho, M.I.N. da Silveira, J. Liq. Chromatogr. Rel. Technol. 22 (1999) 2307-2320.

[22] D.J. Smith, G.D. Paulson, J. Anim. Sci. 75 (1997) 454461.

[23] D.J. Smith, J. Anim. Sci. 76 (1998) 173-194.

[24] M. Deveaux, M. Kintz, J.-P. Goullé, J. Bessard, G. Pépin, D. Gosset, Forensic Sci. Int. 107 (2000) 389-394.

[25] I. Dürsch, H.H.D. Meyer, H. Karg, J. Anim. Sci. 73 (1995) $2050-2053$.

[26] A. Gleixner, H. Sauerwein, H.H.D. Meyer, in: N. Haagsma, A. Ruiter (Eds.), Proceedings of the EuroResidue III Conference on Residues of Veterinary Drugs in Food, Veldhoven, 1996, pp. 411-415.

[27] P. Kintz, V. Dumestre-Toulet, C. Jamey, V. Cirimele, B. Ludes, J. Forensic Sci. 45 (2000) 170-174.

[28] M.J. Sauer, S.P.L. Anderson, Analyst 119 (1994) 25532556.

[29] W. Haasnoot, P. Stouten, R. Schilt, D. Hooijerink, Analyst 123 (1998) 2707-2710. 